\title{
Formação e trabalho dos cirurgiões-dentistas na União Europeia
}

\author{
Andréa Lanzillotti Cardoso*; Márcia Maria Pereira Rendeiro**; Celso da Silva Queiróz***; Fernanda \\ Nunes de Souza ${ }^{* * * * ;}$ Rhayany de Castro Lindenblatt Ribeiro****
}

* Professora Doutora, Cursos de Odontologia da Universidade Estadual do Rio de Janeiro e Uni São José

** Professora Doutora, Curso de Odontologia da Universidade Estadual do Rio de Janeiro

*** Professor Doutor, Cursos de Odontologia da Universidade Estadual do Rio de Janeiro e Universidade Veiga de Almeida

**** Professora Doutora, Curso de Odontologia da Uni São José

Recebido em 11/10/2019. Aprovado em 07/04/2020.

\begin{abstract}
RESUMO
O objetivo do estudo é apresentar a situação atual da de Odontologia na União Europeia, no que tange à formação, ao trânsito de cirurgiões-dentistas, à regulação profissional e às especialidades odontológicas. Para tanto, pautou-se em uma análise documental e revisão bibliográfica da literatura. Foram incluídos apenas artigos científicos publicados na íntegra, em português ou inglês, no período de 2009 a 2018, que estivessem relacionados ao tema da pesquisa. A busca dos artigos foi realizada nas bases de dados SciELO, LILACS e PubMed, por meio da combinação dos descritores: "Trabalho/Work", "Odontologia/Odontology", "Educação Superior/Education, Higher", "União Europeia/European Union". O estudo demonstrou que a União Europeia detém em uma só legislação normas que regulam o trânsito dos cirurgiões-dentistas, embora o domínio da língua pareça ser um entrave à circulação. Ademais, a harmonização da formação da Odontologia foi pactuada no bloco. Nesse sentido, a União Europeia manda recados para o MERCOSUL, do qual o Brasil faz parte. Interessante e necessária é a absorção pelo MERCOSUL das experiências exitosas e desfechos já encontrados pela União Europeia, nesse desafio de planificar a educação superior e o trânsito de cirurgiões-dentistas, considerando as peculiaridades que o compõem.
\end{abstract}

Descritores: Educação Superior. Odontologia. União Europeia. Trabalho.

\section{INTRODUÇÃ̃O}

A integração regional é uma tendência mundial, que partindo de um contexto econômico acaba por atingir a sociedade como um todo ${ }^{1}$, sendo a integração de mercados e a livre circulação de profissionais um dos seus objetivos mais complexos.

Analisar a Odontologia inserida no mercado de trabalho brasileiro, isolando-a das mudanças de contexto sociocultural e político pelo qual passam 
todas as economias já não é suficiente. Aspirações dessa categoria profissional por conhecer o processo regulatório de outros países para uma possível imigração integra o imaginário comum de cirurgiões-dentistas no mundo globalizado. $\mathrm{O}$ processo regulatório compreende a formação, a entrada no mercado de trabalho, o tipo de regulação profissional empreendida em cada país e as práticas de concorrência profissional, como as especializações ${ }^{2}$.

A União Europeia (UE) abrangia 28 nações em 2019 (Reino Unido em processo de saída do Bloco, efetivada em 2020), com Produto Interno Bruto per capita estimado em $\$ 32,700$ e população que ultrapassa os 500 milhões de pessoas. No entanto, na busca de uma unidade regional, muito enfrentamento de ordem política, econômica e social tem sido necessário para dirimir divergências e percalços produzidos por alguns Estados Partes, ratificando os pressupostos de Haas $^{3}$ de que motivações e interesses no processo de integração diferem de um país para outro.

O início da UE ocorreu nos anos 1950, a partir de iniciativas de países, anteriormente antagônicos, com a idéia de que somente a integração política e econômica poderia evitar que novas guerras assolassem a Europa. Cinco tratados foram celebrados até o Tratado de Maastricht, que instituiu a União Europeia em $1993^{4}$.

$\mathrm{Na}$ visão de Silva $^{5}$ os alargamentos sucessivos da UE constituem mais um aumento de desafios. Segundo a autora, os cidadãos da UE vêm enfrentando o aumento do desemprego, o custo crescente do regime de pensões, aumentos da sobrecarga fiscal e social sobre os Estados.

A intensificação da integração regional levou à constituição de organismos supranacionais na UE. Deste modo, o Conselho Europeu, instância maior da UE, define a direção e as prioridades políticas gerais. Com relação ao processo legislativo, as decisões são tomadas pelo triângulo institucional constituído pelo Conselho da UE, pelo
Parlamento Europeu e pela Comissão Europeia. No âmbito legislativo foi instituído o Tribunal de Justiça e o Tribunal de Contas ${ }^{6}$.

No setor de serviços de saúde está a Odontologia, arrolada nesse processo de unificação, aprofundado a tal ponto que permite a livre circulação de profissionais. $\mathrm{O}$ objetivo desse estudo é apresentar a situação atual da de Odontologia na UE, no que tange à formação, ao trânsito de cirurgiões-dentistas, à regulação profissional e às especialidades odontológicas.

\section{REVISÃO DE LITERATURA}

O presente estudo se trata de uma análise documental e revisão bibliográfica não exaustiva da literatura. A análise documental foi necessária, visto um contingente de padronizações adotadas pela UE para o deslindar de nós críticos a fim de atingir um dos objetivos do Bloco que é a livre circulação de profissionais.

O trabalho de revisão de literatura foi conduzido com base nos seguintes critérios de inclusão: artigos científicos publicados na íntegra, em português, espanhol ou inglês, no período de 2009 a 2018, que estivessem relacionados ao tema dessa pesquisa. Foram excluídos artigos que versavam sobre o ensino superior, mas que não especificassem a Odontologia.

A busca dos artigos foi realizada nas bases de dados Scientific Eletronic Library Online (SciELO), Literatura Latino-americana e do Caribe em Ciências da Saúde (LILACS) e United States National Institutes of Health's National Library of Medicine (PubMed), por meio da combinação - utilizando o operador booleano "AND" - dos descritores, em português e inglês: "Trabalho/Work", "Odontologia/Odontology", "Educação Superior/Education, Higher", "União Europeia/European Union". A figura 1 demonstra o diagrama de fluxo da pesquisa bibliográfica. 


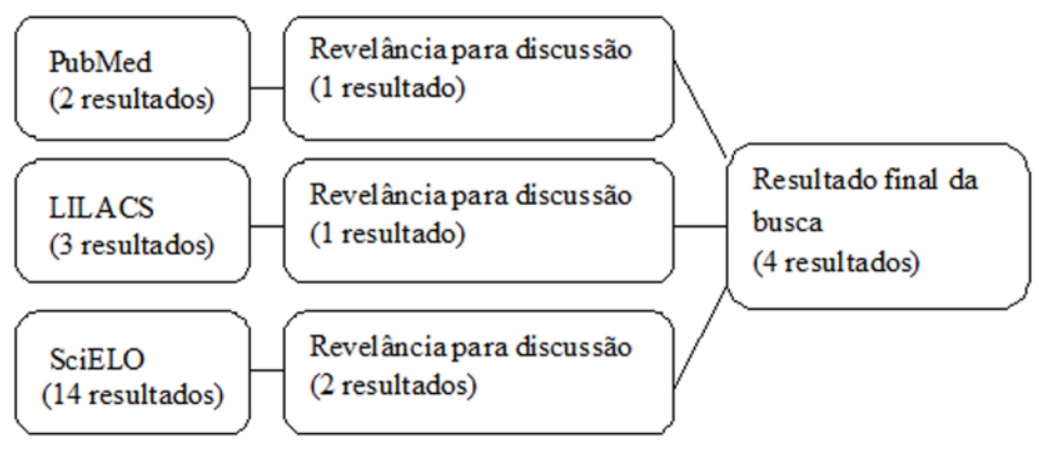

Figura 1. Diagrama de Fluxo de pesquisa bibliográfica para a combinação dos termos em português e inglês: "Trabalho/Work", "Odontologia/Odontology", "Educação Superior/Education, Higher", "União Europeia/European Union"

\section{Formação e livre trânsito de profissionais na União Europeia}

Com relação a este tema, a legislação da UE tem sido abundante. Já no seu início estiveram afixados no Tratado de Roma o objetivo de se concretizar a formação de um mercado único engloba as quatro liberdades: bens, pessoas, serviços e capitais. Esses objetivos foram reforçados com o Ato Único Europeu e com o Tratado de Maastricht ${ }^{6}$.

O processo de reconhecimento de diplomas na UE, dependendo da profissão do indivíduo, pode ser complexo e dispendioso. Há uma distinção entre o reconhecimento acadêmico e o profissional. Enquanto o propósito do reconhecimento acadêmico seja, na maioria das vezes, o prosseguimento de estudos, embora possa também servir para efeitos profissionais; o objetivo do reconhecimento profissional é somente para exercício de uma determinada profissão ${ }^{7}$.

Entre as décadas de 1970 e 1980, diretivas (orientações) foram estabelecidas com o propósito de harmonizar as formações e estabelecer um conjunto mínimo de condições que a formação deva satisfazer para que houvesse o reconhecimento profissional de formações concluídas nos Estados Partes da UE. Autores como Peixoto $^{8}$ e Silva $^{5}$ relatam que, à época, em vista da morosidade da criação destas diretivas adotou-se também uma abordagem "geral" entre as profissões, baseada na confiança de que há qualidade na formação profissional desempenhada por cada Estado Parte.

Várias diretivas foram adotadas no sentido de facilitar o reconhecimento das qualificações profissionais, mas foi a consolidação num ato legislativo único por meio da diretiva 2005/36/CE; que efetivamente simplificou os procedimentos administrativos ${ }^{4}$.

\section{Regulação sobre o reconhecimento profissional}

O reconhecimento profissional é a autorização para o exercício de uma profissão em um país de acolhimento por um órgão competente, que regula o exercício de uma determinada profissão ou atividade profissional regulamentada neste país.

Este processo tem por base o princípio da confiança mútua entre os Estados Partes, como já exposto, e pressupõe que a formação acadêmica e profissional possa variar entre os países, mas não é impeditiva do exercício dessa profissão em outro Estado Parte, que não aquele onde o indivíduo obteve a sua formação. Sustenta este princípio, dois pilares: os sistemas 
nacionais de acreditação de qualidade e os sistemas de informação.

A diretiva no. 36/2005/CE, descrita anteriormente, apresenta três sistemas para o reconhecimento das qualificações:

a - Um sistema geral para profissões regulamentadas, onde o país de acolhimento pode indeferir ou mesmo forçar o profissional a se submeter à formação adicional e exames, para que o diploma seja reconhecido para efeitos profissionais;

b - O reconhecimento com base na experiência profissional, mais comum em comércio e indústria;

c - Um sistema de reconhecimento automático, aplicado às profissões setoriais, dentre elas a Odontologia. Dessa forma, os profissionais registrados no órgão competente de um país da UE podem cadastrar-se para a prática em qualquer outro país do Bloco, tendo reconhecimento automático garantido ${ }^{7}$.

O reconhecimento automático das profissões setoriais tem seu fundamento na harmonização da formação das mesmas, pactuadas no âmbito do Bloco e estabelecidas, no caso da odontologia, na seção 4 da diretiva 36/2005/CE; com a finalidade de facilitar a mobilidade de profissionais. Além da Odontologia a Comunidade Econômica Europeia reconhece como profissões setoriais: a Medicina, Medicina Veterinária, Enfermagem, Farmácia, Parteiras (enfermagem voltada para saúde materna e obstétrica) e Arquitetura.

A Odontologia é uma profissão reconhecida em todos os Estados Partes e as autoridades dos países de acolhimento obrigatoriamente devem reconhecer as qualificações dos dentistas generalistas. A harmonização de sua formação pressupõe que o curso tenha pelo menos cinco anos de estudo em tempo integral e englobe conhecimentos $\mathrm{e}$ competências enumerados no artigo $n^{\circ}$. 34, que dispõe sobre a formação do dentista generalista e o anexo V.5.3.1 da mesma diretiva, onde estão assinaladas as disciplinas mínimas a serem cursadas na formação em Odontologia. A estrutura curricular foi dividida em três blocos: disciplinas de base; médico-biológicas e médicas gerais; e disciplinas especificamente odontoestomatológicas ${ }^{9}$.

O quadro 1 exibe o país, ano em que os dados foram disponibilizados, número, categoria administrativa, duração, número de ingressantes, egressos e percentual de mulheres nos cursos de Odontologia na UE. Pode-se perceber que 57\% dos países adotam o intervalo de tempo de cinco anos para a graduação, tempo mínimo pactuado no âmbito do Bloco. Ao todo a UE forma $80,42 \%$ de seus ingressantes e sua dependência administrativa é majoritariamente pública (87\%). Ressalta-se o fato de que apesar do contingente de mulheres em formação ultrapassar a metade (89\%), ainda não houve reflexo no mercado de trabalho, no qual ainda se sobrepõe o sexo masculino. Com relação ao número de faculdades, destaque deve ser dado à Itália, com 34 instituições de ensino; enquanto Estônia, Letônia, Malta e Eslovênia detêm apenas uma instituição formadora cada e cuja dependência administrativa é pública.

\section{Distribuição de cirurgiões-dentistas na UE}

Associações profissionais na UE deflagram que, apesar do aumento contínuo no número de cirurgiões-dentistas em todo o Bloco, a distribuição geográfica continua a ser desigual, com pouca assistência em áreas rurais, implicando em deslocamento de indivíduos residentes nessas regiões para zonas urbanas, a fim de ter acesso ao tratamento odontologico. Políticas de incentivos formais são raras e, mais comumente, comunidades rurais promovem, de forma isolada, oportunidades para atrair profissionais. 
Quadro 1. País, ano em que os dados foram disponibilizados, número, natureza administrativa, duração do curso, número de ingressantes e egressos, e percentual de mulheres entre os estudantes nos cursos de Odontologia da UE

\begin{tabular}{|c|c|c|c|c|c|c|c|c|}
\hline País & Ano & $\begin{array}{l}\text { Total de } \\
\text { cursos }\end{array}$ & Públicos & Privados & $\begin{array}{c}\text { Duração } \\
\text { (anos) }\end{array}$ & Ingressos & Egressos & $\begin{array}{c}\text { Mulheres } \\
(\%)\end{array}$ \\
\hline Alemanha & 2012 & 30 & 29 & 1 & 5,5 & 2222 & 1813 & 62 \\
\hline Áustria & 2013 & 4 & 4 & 0 & 6 & 165 & 119 & 65 \\
\hline Bélgica & 2012 & 5 & 5 & 0 & 5 & SI & 158 & 80 \\
\hline Bulgária & 2012 & 5 & 5 & 0 & 5,5 & 350 & 290 & 50 \\
\hline Croácia & 2013 & 3 & 2 & 1 & 6 & 148 & 113 & 69 \\
\hline Dinamarca & 2012 & 2 & 2 & 0 & 5 & 162 & 120 & 76 \\
\hline Eslováquia & 2013 & 4 & 2 & 2 & 6 & 117 & 101 & 60 \\
\hline Eslovênia & 2012 & 1 & 1 & 0 & 6 & 70 & 50 & 70 \\
\hline Espanha & 2012 & 17 & 12 & 5 & 5 & 1379 & 1379 & 67 \\
\hline Estônia & 2013 & 1 & 1 & 0 & 5,5 & 32 & 30 & 87 \\
\hline Finlândia & 2013 & 4 & 3 & 1 & 5 & 186 & 100 & 68 \\
\hline França & 2011 & 16 & 16 & 0 & 6 & 1154 & 917 & 55 \\
\hline Grécia & 2012 & 2 & 2 & 0 & 5 & 250 & 275 & 62 \\
\hline Holanda & 2013 & 3 & 3 & 0 & 6 & 243 & 268 & 57 \\
\hline Hungria & 2013 & 4 & 4 & 0 & 5 & 310 & 245 & 58 \\
\hline Irlanda & 2013 & 2 & 2 & 0 & 5 & 86 & 68 & 54 \\
\hline Itália & 2013 & 34 & 32 & 2 & 5 & 984 & 883 & 47 \\
\hline Letônia & 2012 & 1 & 1 & 0 & 5 & 35 & 32 & 87 \\
\hline Lituânia & 2013 & 2 & 2 & 0 & 5 & 161 & 161 & 83 \\
\hline Malta & 2013 & 1 & 1 & 0 & 5 & 8 & 8 & 38 \\
\hline Polônia & 2013 & 10 & 10 & 0 & 5 & 1231 & 809 & 80 \\
\hline Portugal & 2012 & 7 & 3 & 4 & 5 & 716 & 553 & 66 \\
\hline Reino Unido* & 2013 & 16 & 16 & 0 & 5 & 1100 & 1052 & 56 \\
\hline República Checa & 2012 & 5 & 5 & 0 & 5 & 280 & 250 & 38 \\
\hline Romênia & 2013 & 10 & 8 & 2 & 6 & 1800 & 1700 & 70 \\
\hline Suécia & 2012 & 4 & 4 & 0 & 5 & 339 & 200 & 63 \\
\hline Total & & 193 & 175 & 18 & & 13528 & 11694 & \\
\hline
\end{tabular}

Fonte: Adaptado de Kravitz, Treasure ${ }^{10}$ (não exibe informações de Chipre e Luxemburgo). SI: Sem informação. *: Saiu da UE em 2020. 
Uma tendência observada na pesquisa de Wismar et al. ${ }^{11}$ é o fato de que profissionais de saúde são impulsionados a transitar entre os Estados Partes da Europa em busca de mais altos salários, melhores condições de trabalho, treinamento e oportunidades de carreira, ou ainda novas experiências profissionais e pessoais. No entanto, considera-se que a má distribuição geográfica dos cirurgiõesdentistas e demais profissionais de saúde seja uma tendência mundial. Assim como os grandes centros urbanos concentram profissionais, aqueles países que oferecem maior desenvolvimento socioeconômico, maior mercado de trabalho e melhor remuneração são polos de atração para os mesmos.

Atualmente, a UE tem assistido a um contingente muito pequeno de cirurgiões-dentistas que tenta se estabelecer em outro Estado Parte. No entanto, o profissional interessado em se estabelecer em um Estado Parte que não aquele em que se credenciou deve fazer a solicitação à autoridade do Estado Parte de acolhimento. Este pode exigir uma série de documentos e formalidades necessárias ao estabelecimento em outro Estado Parte e emitidos há no máximo três meses, quais sejam: título de formação; certificado das autoridades competentes do Estado Parte de origem, confirmando a existência do referido título; prova de nacionalidade; provas de honorabilidade; de boa conduta ou que suspenda a proibição do exercício da profissão em caso de falta profissional grave ou de infração penal. Ademais, no caso da prestação de serviços temporária é necessário que o profissional também esteja estabelecido legalmente no Estado Parte de origem $^{12}$.

O quadro 2 demonstra o número de cirurgiões-dentistas registrados nos países da UE, os que estão ativos e o contingente populacional. Notese que as informações provenientes de autoridades de cada país condizem com dados obtidos em anos diversos (2007 a 2013), apesar da maior parte deles terem sido divulgados em 2008.
Dos Estados Partes da UE, Malta $(3,38)$, Irlanda $(4,50)$ e Hungria $(4,95)$ são os que detêm a menor relação de cirurgiões-dentistas por 10.000 habitantes, enquanto a maior relação se encontra na Lituânia $(12,18)$, Bulgária $(11,46)$ e Chipre $(9,55)$. Considera-se os dados inusitados, uma vez que o maior número de instituições formadoras estão na Itália (34) e na Alemanha (31), de acordo com o quadro I, sendo que a Alemanha apresenta a maior população de todo o Bloco. A Grécia, além de deter apenas duas universidades, apresenta graves problemas de ordem econômica e PIB inferior ao da Alemanha e Itália.

\section{Regulação dos Profissionais}

$\mathrm{Na}$ UE não existem conselhos profissionais, na maioria dos países a regulação do exercício profissional está a cargo das associações profissionais ou dos sindicatos, sendo que algumas associações também tomam para si o papel de sindicato; em outros, a regulação da profissão é exercida por departamentos específicos dos Ministérios da Saúde.

Em cerca de um terço dos países a adesão a uma associação dental é obrigatória, muitas vezes porque estas também são as autoridades de registro. De acordo com Kravitz e Treasure ${ }^{13}$, nos países onde a adesão é voluntária há uma grande variação. Assim, enquanto na Finlândia 98\% dos cirurgiõesdentistas são associados, na Itália menos da metade são membros das duas principais associações do país.

Embora todos os países tenham uma associação nacional principal, alguns detêm duas ou mais. Já no âmbito da UE existem muitas associações, sociedades de especialistas e comitês representando os cirurgiões-dentistas. As de maior relevância são o Council of European Dentists e o European Union of Dentists. No quadro 3 estão expostos os órgãos responsáveis pela regulação da profissão nos países da UE. 
Quadro 2. País, ano em que os dados foram disponibilizados, população, número de cirurgiõesdentistas registrados e ativos por país da UE

\begin{tabular}{|c|c|c|c|c|}
\hline País & Ano & População & $\begin{array}{l}\text { cirurgiões-dentistas } \\
\text { registrados }\end{array}$ & $\begin{array}{c}\text { cirurgiões-dentistas } \\
\text { ativos }\end{array}$ \\
\hline Alemanha & 2012 & 80.523 .746 & 88.882 & 69.236 \\
\hline Áustria & 2013 & 8.489 .482 & 4.820 & 4.421 \\
\hline Bélgica & 2011 & 11.153 .405 & 8.879 & 7.777 \\
\hline Bulgária & 2013 & 7.282 .041 & 8.350 & 8.350 \\
\hline Chipre & 2013 & 865.878 & 1.073 & 827 \\
\hline Croácia & 2007 & 4.475 .611 & 4.537 & 3.875 \\
\hline Dinamarca & 2013 & 5.605 .836 & 7.989 & 5.161 \\
\hline Eslováquia & 2013 & 5.410 .728 & 3.357 & 3.298 \\
\hline Eslovênia & 2013 & 2.060 .253 & 1.762 & 1.358 \\
\hline Espanha & 2012 & 47.059 .533 & 31.261 & 29.000 \\
\hline Estônia & 2013 & 1.324 .814 & 1.615 & 1.250 \\
\hline Finlândia & 2013 & 5.434 .357 & $5 ; 925$ & 4.500 \\
\hline França & 2012 & 65.657 .000 & 41.505 & 41.505 \\
\hline Grécia & 2013 & 10.772 .967 & 14.125 & 9.000 \\
\hline Holanda & 2013 & 16.789 .800 & 10.780 & 8.773 \\
\hline Hungria & 2013 & 9.906 .000 & 5.500 & 4.973 \\
\hline Irlanda & 2013 & 4.591 .087 & 2.627 & 2.200 \\
\hline Itália & 2012 & 59.685 .227 & 58.723 & 45.896 \\
\hline Letônia & 2012 & 2.178 .443 & 1.724 & 1.474 \\
\hline Lituânia & 2013 & 2.962 .000 & 3.660 & 3.610 \\
\hline Luxemburgo & 2008 & 537.000 & 512 & 452 \\
\hline Malta & 2013 & 421.364 & 230 & 170 \\
\hline Polônia & 2012 & 38.533 .299 & 33.633 & 21.800 \\
\hline Portugal & 2012 & 10.487 .289 & 9.097 & 9.097 \\
\hline Reino Unido* & 2013 & 63.887 .988 & 40.156 & 34.534 \\
\hline República Checa & 2012 & 10.516 .125 & 9.354 & 7.821 \\
\hline Romênia & 2013 & 20.057 .458 & 15.500 & 14.400 \\
\hline Suécia & 2010 & 9.580 .424 & 14.454 & 7.528 \\
\hline Total & & 506.249 .155 & 424.105 & 352.286 \\
\hline
\end{tabular}

Fonte: Adaptado de Kravitz, Treasure ${ }^{10}$. *: Saiu da UE em 2020. 
Quadro 3. Órgãos que regulam os cirurgiões-dentistas nos países da UE

\begin{tabular}{|c|c|}
\hline País & Órgão Regulador \\
\hline Alemanha & Kassenzahnärztliche Vereinigungen \\
\hline Áustria & Austrian Dental Chamber, via organizações regionais \\
\hline Bélgica & Ministério da Saúde \\
\hline Bulgaria & Bulgarian Dental Association, por meio de seus colégios regionais \\
\hline Chipre & Cyprus Dental Council \& Cyprus Dental Association \\
\hline Croácia & Croatian Dental Chamber \\
\hline Dinamarca & National Board of Health \\
\hline Eslováquia & Slovak Chamber of Dentists \\
\hline Eslovênia & Medical Chamber of Slovenia \\
\hline Espanha & Colégios Regionais \\
\hline Estônia & Healthcare Board/General Dental Council \\
\hline Finlândia & National Authority for Medicolegal Affairs \\
\hline França & Ordre National \\
\hline Grécia & Ministério da Saúde, Social Solidarity e Regional Dental Society \\
\hline Holanda & Ministry of Public Health Welfare \& Sport \\
\hline Hungria & Ministério da Saúde \\
\hline Irlanda & Irish Dental Council \\
\hline Itália & Federazione Ordini dei Medici Chirurghi e degli Odontoiatri \\
\hline Letônia & Pauls Stradins' Clinical University Hospital \\
\hline Lituânia & Licensing Committee at the Lithuanian Dental Chamber \\
\hline Luxemburgo & Ministério da Saúde \\
\hline Malta & Sem registro \\
\hline Polônia & Conselhos Regionais \\
\hline Portugal & Ordem dos Médicos Dentistas \\
\hline Reino Unido* & General Dental Council \\
\hline República Checa & Czech Dental Chamber e a autoridade regional \\
\hline Romênia & Romanian Collegiums of Dental Physicians \\
\hline Suécia & National Board of Health and Welfare unit for Qualification and Education \\
\hline
\end{tabular}

Fonte: Adaptado de Kravitz, Treasure ${ }^{10}$. *: Saiu da UE em 2020.

A diretiva deixa o reconhecimento das Cirurgia Oral/Bucomaxilofacial são as duas especialidades odontológicas à livre negociação especialidades reconhecidas formalmente por quase entre Estados Partes, sendo que a Ortodontia e todos os países da UE. Excetuam-se Áustria, 
Espanha e Luxemburgo, que não reconhecem o conceito de especialidades em Odontologia. Entretanto, na Áustria, é possível se habilitar em qualquer uma das 3 universidades na "subespecialidade" da cirurgia oral por mais 3 anos de educação.

As outras especialidades mais comuns são a Cirurgia e a Prótese. Conforme pode ser verificado no quadro 4, estas são formalmente reconhecidas em treze e onze países, respectivamente. Muitas outras especialidades têm reconhecimento nacional de várias maneiras (por exemplo, treinamento formal, departamentos de escolas de Odontologia) em diferentes países, mas podem não ser formalmente reconhecidas nos termos da Diretiva Odontológica da UE.

$\mathrm{Na}$ maioria dos países os pacientes podem acessar especialistas diretamente, sem a necessidade de passar por um clínico geral. No entanto, na Estônia, Irlanda, Itália, Letônia, Portugal, Eslovênia, Suécia e Reino Unido, um encaminhamento de um dentista clínico geral é necessário ${ }^{14}$.

Quadro 4. País, ano em que os dados foram disponibilizados, número de profissionais registrados por especialidade nos Estados Partes

\begin{tabular}{|c|c|c|c|c|c|c|c|c|c|c|}
\hline País & Ano & $\begin{array}{c}\text { Orto- } \\
\text { dontia }\end{array}$ & $\begin{array}{c}\text { Cirurgia } \\
\text { Oral }\end{array}$ & $\begin{array}{c}\text { Cirurgia } \\
\text { BMF }\end{array}$ & $\begin{array}{l}\text { Endo- } \\
\text { dontia }\end{array}$ & $\begin{array}{l}\text { Odonto- } \\
\text { pediatria }\end{array}$ & $\begin{array}{l}\text { Perio- } \\
\text { dontia }\end{array}$ & Prótese & $\begin{array}{c}\text { Saúde } \\
\text { Pública } \\
\text { Oral }\end{array}$ & Outras \\
\hline Alemanha & 2012 & 3443 & 2552 & - & - & - & - & - & 460 & Não \\
\hline Áustria & 2013 & - & - & 167 & - & - & - & - & - & Não \\
\hline Bélgica & 2011 & 399 & - & 290 & - & - & 139 & - & - & Não \\
\hline Bulgária & 2013 & 45 & 266 & 45 & 417 & 580 & 36 & 115 & 17 & Sim \\
\hline Chipre & 2013 & 46 & 12 & - & - & - & - & - & - & Não \\
\hline Croácia & 2013 & 184 & 98 & - & 97 & 130 & 74 & 156 & - & Sim \\
\hline Dinamarca & 2013 & 290 & - & 98 & - & - & - & - & - & Não \\
\hline Eslováquia & 2013 & 193 & 192 & 26 & - & 39 & 95 & 64 & - & Não \\
\hline Eslovênia & 2013 & 84 & 24 & 34 & 24 & 36 & 16 & 24 & - & Não \\
\hline Estônia & 2013 & 62 & - & 25 & - & - & - & - & - & $\operatorname{Sim}$ \\
\hline Finlândia & 2013 & 156 & - & 104 & - & - & - & - & 90 & Sim \\
\hline França & 2012 & 1981 & - & - & - & - & - & - & - & Não \\
\hline Grécia & 2013 & 476 & - & 174 & - & - & - & - & - & Não \\
\hline Holanda & 2013 & 331 & - & 265 & 73 & 46 & 81 & - & - & Não \\
\hline Hungria & 2013 & 379 & 139 & 157 & - & 254 & 65 & 924 & - & Não \\
\hline Irlanda & 2013 & 140 & 49 & 5 & - & - & - & - & - & Não \\
\hline Itália & 2012 & 1795 & - & 640 & - & - & - & - & - & Não \\
\hline Letônia & 2012 & 24 & - & 39 & 10 & 23 & 0 & 19 & - & Não \\
\hline Lituânia & 2013 & 93 & 92 & 23 & 44 & 56 & 57 & 270 & - & Não \\
\hline Malta & 2013 & 7 & - & 1 & 9 & 2 & 3 & 3 & 3 & Sim \\
\hline Polônia & 2012 & 1115 & 405 & 227 & 1561 & 486 & 420 & 1453 & 71 & Não \\
\hline Portugal & 2012 & 51 & 4 & 93 & - & - & - & - & - & Não \\
\hline Reino Unido* & 2013 & 1343 & 754 & - & 250 & 246 & 333 & 431 & 117 & Sim \\
\hline República Checa & 2012 & 337 & - & 72 & - & - & - & - & - & Não \\
\hline Romênia & 2008 & 412 & 157 & 234 & - & - & - & - & - & Não \\
\hline Suécia & 2010 & 265 & - & 145 & 47 & 83 & 101 & 134 & - & Sim \\
\hline Total & & 13651 & 4744 & 2864 & 2532 & 1981 & 1420 & 3593 & 758 & \\
\hline
\end{tabular}

Fonte: Adaptado de Kravitz, Treasure ${ }^{10}$ (não exibe informações de Espanha e Luxemburgo). BMF: Bucomaxilofacial. *: Saiu da UE em 2020. 
As especialidades profissionais também conformam a regulação do exercício profissional, no entendimento de que são consideradas práticas de concorrência. Pode-se observar, neste momento, como a cultura pode influenciar a regulação do exercício profissional. Nos países europeus, por exemplo, a lógica é de que quanto maior o número de especialistas, mais segmentado se tornará o mercado de trabalho e maior será a concorrência por clientes. Deste modo, o número de especialistas na UE é muito baixo, com relação ao número de cirurgiões-dentistas ativos.

Numa visão sociológica, Freison ${ }^{15}$ sustenta que a tendência à especialização contribui para a desprofissionalização e a proletarização, uma vez que pode-se esperar que profissionais cada vez mais limitados - pelo trabalho repetitivo, possam perder o controle de todo um processo cuja especialidade é apenas um fragmento. Entende-se que há sim uma segmentação do mercado quando do aumento de profissionais especializados. No entanto, a expertise é necessária, pois são tantos os conhecimentos requeridos consequentes de novas tecnologias, descobertas e protocolos advindos de pesquisas que inviabilizam que um profissional os detenha "com excelência" em todos os campos.

Ainda com relação às práticas de concorrência entre membros da própria profissão, é relevante destacar que não há um código de ética único na União Europeia. A orientação ética é em grande parte observada pelas associações nacionais ou, em determinados países pelo órgão regulador da profissão. No entanto, a aplicação de sanções é realizada por comissões a nível local.

\section{CONSIDERAÇÕES FINAIS}

Conforme o exposto, a UE conseguiu reunir em uma só legislação, a diretiva 36/2005/CE, normas que regulam o trânsito dos cirurgiõesdentistas e parece ter sido a mais acertada decisão neste processo de integração dos serviços. Excetuando-se a questão de domínio da língua, que diante tantas nações, passa a se constituir um entrave à circulação, a harmonização da formação das profissões setoriais, dentre elas a Odontologia. A legislação atual é fruto de um amadurecimento de proposições anteriores de um Bloco que vem se submetendo ao processo integratório por mais de meio século. Nesta perspectiva, a UE manda recados para o MERCOSUL, do qual o Brasil faz parte. Interessante e necessária é a absorção pelo MERCOSUL das experiências exitosas e desfechos já encontrados pela UE, nesse desafio de planificar a educação superior, considerando as peculiaridades que o compõem.

\section{ABSTRACT \\ Training and work of dental surgeons in the European Union}

The aim of the study is to present the current situation of Dentistry in the European Union, with regard to the training, international mobility of dentists, professional regulation and dental specialties. In order to do so, a documental analysis and review of the literature was carried out. Only scientific articles published in full, in Portuguese or English, from 2009 to 2018, that were related to the research topic were included. The search for the articles was carried out in the SciELO, LILACS and PubMed databases, through the combination of the descriptors: "Work", "Dentistry", "Higher Education", "European Union". The study showed that the European Union has in one legislation rules that regulate the mobility of dentists, although the issue of the language seems to be an obstacle to such circulation. Furthermore, the harmonization of the formation of Dentistry was agreed among members of the bloc. In this sense, the European Union sends messages to MERCOSUL, group in which Brazil is a member. The absorption by MERCOSUL of the successful experiences and outcomes already found by the European Union is somehow interesting and necessary, in a matter of higher education and the mobility of dentists, considering the peculiarities that compose it.

Descriptors: Education, Higher. Dentistry. European Union. Work. 


\section{REFERÊNCIAS}

1. Pinto HEM. A Estratégia e Integração Econômica Regional na América Latina: o caso da Comunidade Andina. [Tese de Doutorado] Programa de Integração da América Latina da Universidade de São Paulo. São Paulo: USP, 2006.

2. Cardoso AL. Odontólogos brasileiros e a demanda de políticas regulatórias para o exercício profissional no âmbito do MERCOSUL. [Tese de Doutorado]. Rio de Janeiro: FIOCRUZ, 2013.

3. Haas EB. The Uniting of Europe: Political, Social and Economic Forces. Londres: Stevens, 1958.

4. European Comission. The EU Single Market. Directive 2005/36/EC_Policy Developments. [Acesso em 10/01/2018]. Disponível em: http://ec.europa.eu/ internal_market/qualifications/policy_devel opments/legislation_en.htm.

5. Silva LEFP. Reconhecimento das Qualificações Acadêmicas e Profissionais na UE - Entrave ou Motor à Mobilidade. [Dissertação de Mestrado]. Lisboa: Universidade Nova de Lisboa, 2010.

6. União Europeia. A Europa em 12 lições. [Acesso em 10/01/2018]. Disponível em: http://europa.eu/abc/12lessons/lesson2/inde x_pt.htm.

7. União Europeia. $\mathrm{O}$ tratado em poucas palavras. [Acesso em 10/01/2018]. Disponível em: http://europa.eu/liston treaty/glance/index_pt.htm.

8. Peixoto J. Migrações e Políticas Migratórias na União europeia: livre circulação e reconhecimento de diplomas. Análise Social, 2001; 36: 153-83.

9. Official Journal of the European Union. European Parliament and of the Council Directive Number 2005/36/EC of $07 / 09 / 2005$ on the Recognition of
Professional Qualifications, 2005; 255/22:121.

10. Kravitz A, Treasure E. Manual of Dental Practice. The Council of European Dentists, 2015.

11. Wismar M, Maier CB, Glinos IA, Dussault G, Figueras J. Health Professional Mobility and Health Systems: Evidence from 17 European Countries. World Health Organization, European Observatory on Health Systems and Policies, 2011; 13(2): 18-27.

12. Widstrõm E, Eaton KA. Factors guiding the number of dental specialist in the European Union and Economic Area. Den Norske Tannlege forenings. Tidende; 2006, 116 (11):37-48.

13. Kravitz A, Treasure E. Manual of Dental Practice. The Council of European Dentists, 2008.

14. Jones E, Bijl N. Van der. Public Opinion and Elargement. European Union politics. London, 2004; 5 (3): 331-51.

15. Freidson E. Renascimento do Profissionalismo: Teoria, Profecia e Política. São Paulo: EDUSP, 2001.

\section{Correspondência para:}

Andréa Lanzillotti Cardoso e-mail: andrealanzi.ppc@gmail.com Av. 28 de Setembro, 157 Vila Isabel 20551-030 Rio de Janeiro/RJ 